\title{
Análise ergonômica comparativa entre estabelecimentos de serviços de alimentação em campus universitário
}

\section{Comparative ergonomic analysis between university campus food service establishments}

THAISA SAMPAIO SARMENTO Arquiteta e Urbanista, Mestre em Arquitetura e Urbanismo, Doutora em Design, e-mail: thaisa.sampaio@fau.ufal.br

ANA WANESSA SAMPAIO MENDONÇA SIMÕES Graduanda em Arquitetura e Urbanismo, e-mail: anawanessasampaio@hotmail.com

ÁGUEDA PARANHOS FERRO

Graduanda em Design, e-mail: agueda_d15@hotmail.com

\section{RESUMO}

Os ambientes de restaurantes devem atender às suas necessidades tanto dos clientes, como dos funcionários, assegurando critérios dimensionais, promovendo a autonomia, a segurança e a satisfação do maior número de pessoas, já que se destinam a atender um público amplo. Há uma preocupação crescente de arquitetos e designers em produzir ambientes de qualidade estética, funcional e com segurança, enriquecendo espaços de alimentação com elementos que possam dar ênfase ao bem-estar dos clientes, enquanto consomem. A Ergonomia e a Psicologia Ambiental colaboram com análises de ambientes de uso público, a fim de compreender o uso e o comportamento dos usuários, gerando subsídios para que novos projetos sejam pensados com critérios de inclusão das necessidades e anseios dos usuários e trabalhadores. Este artigo realiza uma análise ergonômica comparativa entre três estabelecimentos de alimentação em um campus universitário, a fim de verificar as condições de alimentação vivenciadas pela comunidade estudantil e as condições de infraestrutura nas quais as edificações foram projetadas. A metodologia ergonômica utilizada é baseada em Villarouco $(2009,2011)$ e Maciel et al. (2018). Os resultados são organizados em tabelas sintéticas comparativas sobre dados físicos e ambientais e dados do comportamento e percepção dos usuários.

PALAVRAS - CHAVE: Ergonomia do ambiente construído, restaurantes, campus universitário.

\section{ABSTRACT}

Restaurant environments must support both customers' and employees' needs. It is necessary to ensure dimensional criteria, to promote autonomy, security and satisfaction of the largest number of 


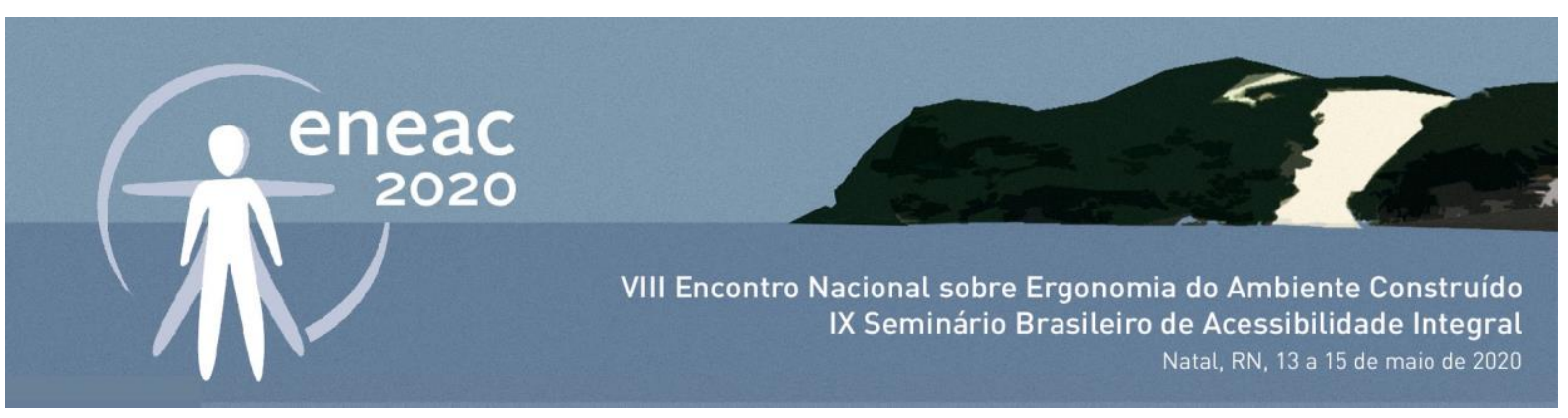

users. There is a concern of architects and designers about the responsibility to produce architectural spaces according aesthetic, functional and safely quality conditions. An actual tendency is to enrich food spaces with elements that emphasize human well-being while consuming. Ergonomics and Environmental Psychology collaborate to public spaces analyses in order to understand users' behavior and needs while doing a different range of activities, and consequently generate subsidies for inclusivity principles for architectural design. This article performs a comparative ergonomic analysis between three food establishments at an university campus, in order to verify users' experience inside this restaurants and to analyses offered infrastructure conditions. The ergonomic methodology used is based on Villarouco $(2009,2011)$ and Maciel et al. (2018). Results are organized into comparative synthetic tables about physical and environmental data and users' behavior and perception data.

KEYWORDS: Ergonomics of the built environment; restaurants; college campus.

\section{INTRODUÇÃO}

Ambientes comerciais são utilizados diariamente por diversos tipos de pessoas, com o objetivo de usufruir de produtos e serviços quando estão em atividades de trabalho, lazer e/ou estudo. Em relação a ambientes de alimentação, nota-se uma preocupação crescente de arquitetos, designers e engenheiros em produzir ambientes de qualidade estética e funcional, que possam promover o consumo dos produtos de alimentação, com segurança, e ainda assim proporcionar uma experiência agradável ao público alvo do estabelecimento. Os projetos de interiores de restaurantes, lanchonetes, cafeterias, bares e panificações estão sendo enriquecidos de elementos que possam dar ênfase ao bem-estar dos clientes, enquanto consomem, estimulando uma maior permanência nos locais de venda.

A Ergonomia se coloca nesse contexto como a base científica que estuda a tarefa realizada pelo indivíduo no ambiente de trabalho e a adaptação dos meios para a realização das tarefas, de acordo com as características e necessidades humanas. A Psicologia Ambiental, por sua vez, estuda a relação entre o ambiente construído e o comportamento dos indivíduos (SILVEIRA; BINS ELY, 2015). Tais disciplinas auxiliaram os pesquisadores a definir estratégias de análise dos ambientes estudados, e assim obter dados para melhor adequação de espaços de alimentação similares, em futuros projetos.

No ambiente universitário, serviços de alimentação são essenciais, garantindo a permanência dos estudantes, servidores e demais frequentadores enquanto realizam atividades de aprendizagem e pesquisa. Na Universidade Federal de Alagoas, Campus A. C. Simões, existem cerca de 10 espaços formais de alimentação - cantinas e restaurantes de pequeno porte, que funcionam via contrato de cessão de uso de espaço físico a empresas privadas (contratos registrados entre 2013 e 2018), mais 1 restaurante universitário - $\mathrm{RU}$, que atendem a um fluxo de cerca de 15 mil estudantes (Censo UFAL, 2018), quase que diariamente. Os espaços de alimentação são construídos pela instituição de ensino superior e disponibilizados ás empresas locadoras, a fim de que possam prestar serviços de alimentação à comunidade universitária. 


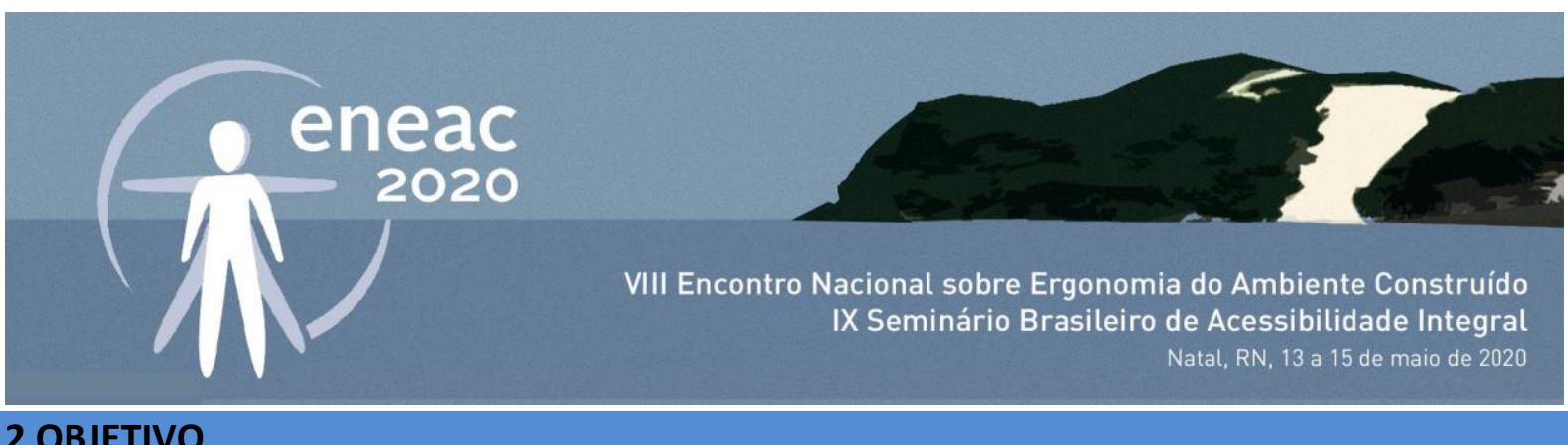

2 OBJETIVO

O objetivo deste artigo foi de realizar uma análise ergonômica comparativa entre estabelecimentos de alimentação no Campus A. C. Simões da Universidade Federal de Alagoas, em Maceió, e observar o uso, a circulação e as condições de conforto, ergonomia e acessibilidade nesses estabelecimentos. As técnicas e métodos utilizados foram aplicados em 03 estudos de caso, realizados nos anos de 2018 e 2019, como parte da disciplina de Projeto de Interiores 2, dos cursos de Arquitetura e Urbanismo e Design da UFAL.

Os estabelecimentos escolhidos fazem parte de Unidades Acadêmicas (UA) da UFAL, onde realizamse atividades de ensino, pesquisa, extensão e gestão universitária. Estes ambientes além de proporcionarem a venda e o consumo de alimentos, bebidas e lanches, também funcionam como espaços de interação social, encontros, reuniões e tantas outras atividades universitárias, que vão muito além das aulas.

\section{METODOLOGIA}

A metodologia utilizada é baseada em Villarouco $(2009,2011)$ e Maciel et al. (2018). Os citados autores utilizam ferramentas de ergonomia do ambiente construído e de psicologia ambiental para realizarem análises de ambientes internos. As principais etapas da pesquisa foram:

- Fase 1: Pesquisa bibliográfica e documental para elaboração do referencial teórico e elaboração das ferramentas das análises;

- Fase 2: Análise Global do Ambiente (etapa pertencente a MEAC de Villarouco (2009)): Visitas exploratórias para coleta de dados primários sobre aspectos físicos, dimensionais, funcionais, fotografias e análise preliminar dos pesquisadores;

- Fase 3: Identificação da Configuração Ambiental (etapa pertencente a MEAC de Villarouco (2009)): Observação sobre os princípios fundamentais da ergonomia, análise das tarefas desempenhadas, estudo dos postos de trabalho, aferição do dimensionamento e dos índices de desempenho ambiental e da acessibilidade de cada estabelecimento.

- Fase 4: Avaliação do Ambiente em Uso: Verificação das condições do uso dos estabelecimentos, e observação do comportamento dos usuários, durante a realização de tarefas prescritas;

- Fase 5: Análise da Percepção Ambiental: Levantamento de dados da observação do comportamento dos usuários e aplicação de entrevistas;

- Fase 6: Elaboração do Diagnóstico Ergonômico: Análise dos dados coletados e elaboração da síntese comparativa entre os estabelecimentos analisados. Os dados coletados e analisados são apresentados no item 5.

\section{REFERENCIAL TEÓRICO}

Restaurantes operam em um ritmo de trabalho intenso, num mercado competitivo, que precisa atender a uma série de normas de segurança e qualidade. Em espaços internos de trabalho, como cozinhas e áreas de serviços, é comum encontrar trabalhadores em espaços muito reduzidos, 
realizando tarefas que necessitam de atenção, postura em pé, manuseio de instrumentos cortantes, fogo, água e objetos pesados.

Matos (2000) afirma que no Brasil a produção de refeições exige dos operadores alta produtividade em tempo limitado, muitas vezes em condições inadequadas de trabalho, com problemas de organização espacial, equipamentos e processos, aumentando o grau de insatisfação, cansaço, redução de produtividade, assim como possíveis problemas de saúde.

A atividade de preparar alimentações se caracteriza pela realização de movimentos repetitivos, por vezes com levantamento de peso excessivo e permanência por períodos prolongados na posição em pé. Além disso, os trabalhadores sofrem pressão para adaptarem suas produções aos horários de consumo das refeições o que acaba levando a insatisfação, cansaço, queda de produtividade, problemas de saúde e em alguns casos acidentes de trabalho (SANT'ANA et al.,1994).

As tendências de mercado de alimentação envolvem a autosseleção (balcões de alimentos, bufês em praças de alimentação, com ou sem garçons); variedade de produtos (cozinha aberta para visualização ou visitação), comidas para levar, serviço de entrega; confiança (atenção a higiene, responsabilidade ambiental, opções saudáveis no cardápio, preços justos e acessíveis, reforço de marca. Os serviços de alimentação em instituições podem ser agrupados (se existir um refeitório central) ou dispersos (em diferentes pontos dentro da instituição). Os restaurantes avaliados na UFAL são do tipo terceirizado. É fundamental considerar o acesso a veículos e cargas, para entrega de mercadorias e a coleta do lixo. A aparência externa também é importante, já que a autopromoção, a acessibilidade física, a visualização e legibilidade do cardápio são fundamentais para o sucesso do comércio de alimentos.

Existem três processos importantes que envolvem o serviço de alimentação. Cada um dos processos exigem um dimensionamento preciso para acomodar os usuários durante a execução das atividades (ver quadro 01).

Quadro 1: Distribuição das tarefas num serviço de alimentação e a descrição de seus processos.

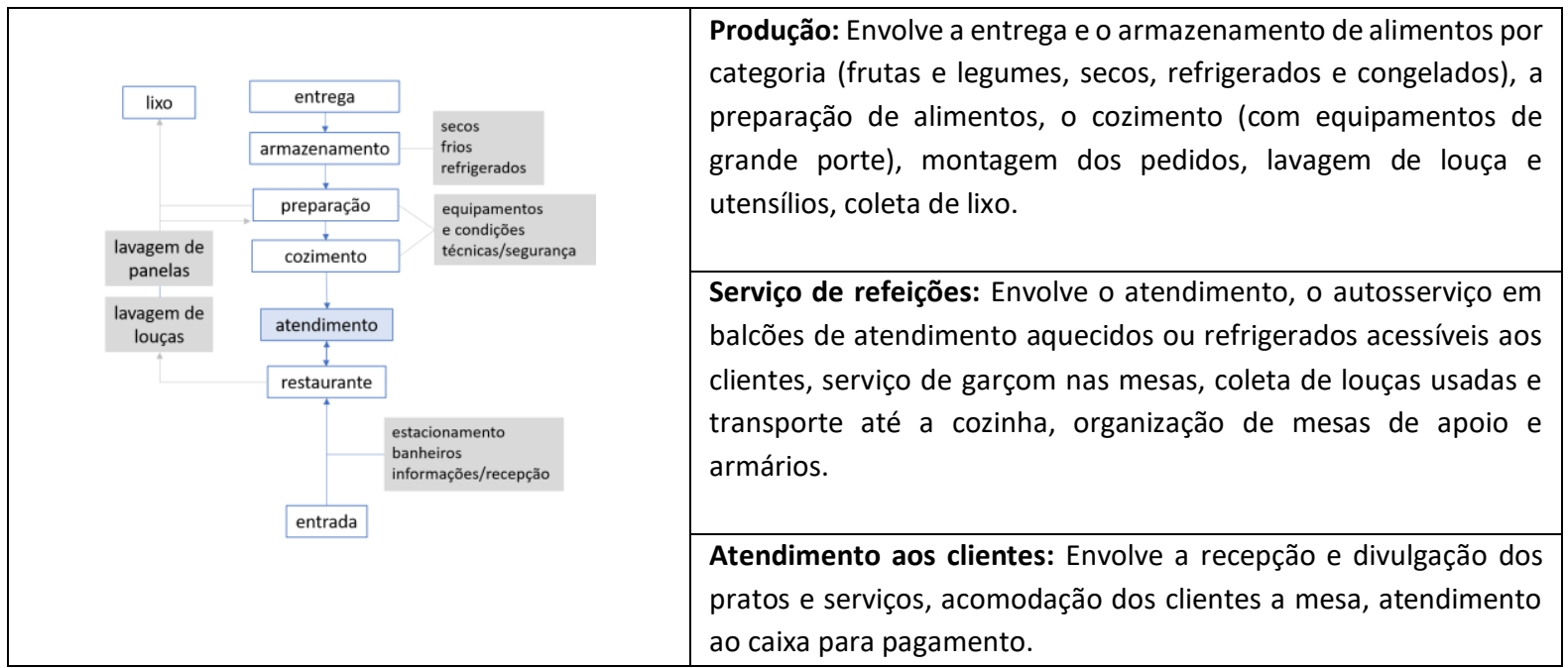




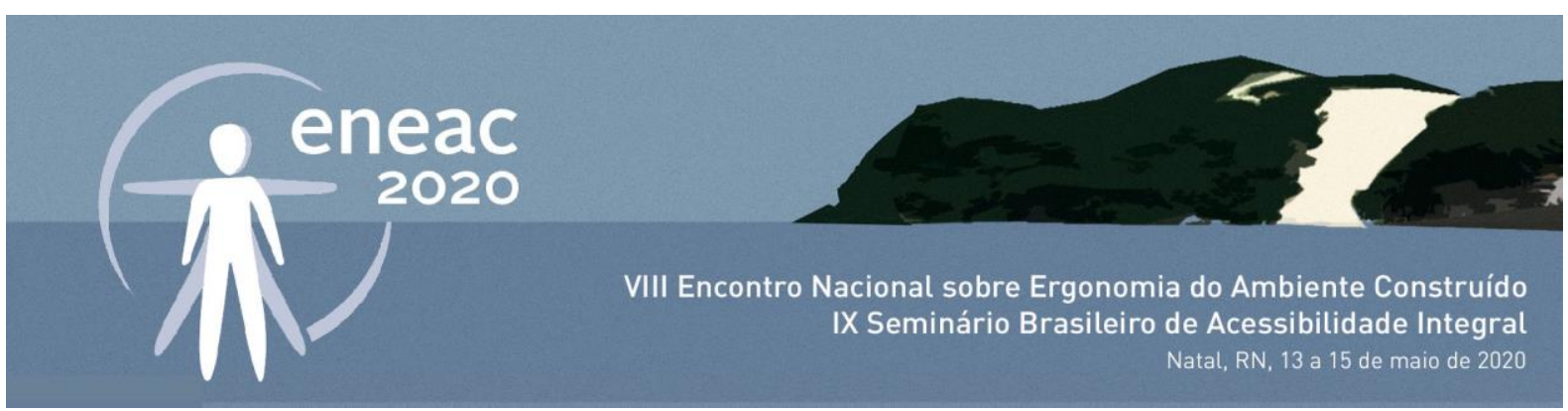

As considerações sobre o serviço de alimentação devem incluir:

- Funções: operação, eficiência, ordem, higiene, durabilidade, manutenção;

- Ambiência: estilo, conceito, conforto, aparência, acessibilidade, comunicação com o cliente;

- Disposição de mesas: proporção do salão, posicionamento de aberturas, condições de circulação e acesso aos produtos;

- Percepção: atenção aos detalhes do serviço e a qualidade dos produtos oferecidos.

Sarmento e Villarouco (2019) defendem que deve-se desenvolver o layout dos ambientes com base em otimizar as zonas de permanência e de circulação de pessoas, aumento da segurança na realização das atividades, estabelecer a frequência de uso de equipamentos e zonas de agrupamento funcional das tarefas, interações com equipamentos e mobiliário, estabelecer critérios de proximidade e acessibilidade, para verificar a intensidade fluxo.

Em cantinas, a operação envolve atender muitas refeições por turno, sendo a demanda concentrada em horários específicos. O fluxo médio de clientes pode variar entre 6 - 9 pessoas/minuto. A proporção é determinada pela rapidez do serviço, atendimento de bebidas, pagamento e opções no cardápio. Se houver fila dupla para pagamento, o fluxo pode chegar a 14-16 pessoas por minuto. O layout deve permitir livre acesso entre cozinha e balcão a fim de facilitar o abastecimento de alimentos quentes, e também, frios. Os balcões devem acomodar os alimentos, bandejas e protegê-los de contaminação. Os caixas ficam ao final da fila, podendo ser duplicados, assim como acomodar caixas de talheres e espaço para bandejas, evitando congestionamentos.

\subsection{Mobiliário em restaurantes de autosserviço:}

O autosserviço exige corredores amplos junto aos balcões, filas ordenadas de mesas. Em sua maioria, esse tipo de restaurante oferece mesa para 4 ou 2 pessoas, quadradas ou redondas. É recomendável adotar mesas e cadeiras soltas, garantindo a acessibilidade e a flexibilidade do layout. O dimensionamento das mesas de 4 lugares varia entre $900 \times 950 \mathrm{~cm}$ a $1500 \times 750 \mathrm{~cm}$ (mesa quadrada) ou $850 \mathrm{~cm}$ a $1050 \mathrm{~cm}$ (diâmetro para mesa redonda). As mesas e cadeiras de empilhar facilitam a retirada e a higienização do lugar, assim como tampos extensíveis ou removíveis facilitam a modificação da forma de acomodação, e acréscimo de lugares a mesa. $O$ dimensionamento da cozinha é dado em função do tipo e do número de lugares atendidos no período do pico da maior demanda - almoço ou jantar (ver Tabela 1). As áreas de preparação devem ocupar $50 \%$ da cozinha. O restante deve ser ocupado por depósitos, instalações e equipamentos de funcionários. $50 \%$ da área da cozinha deve ser de circulação e acesso, 30\% destinado a equipamentos e de 20 a $10 \%$ para bancadas e pias. Em cozinhas de pequeno porte recomenda-se o layout de balcões fixados nas paredes e circulação central. O dimensionamento de balcões e demais itens da área de armazenamento e preparação estão descritas na Tabela 2.

Tabela 1: Área da cozinha em função do tipo de restaurante

\begin{tabular}{|l|c|l|}
\hline Tipo de restaurante & $\begin{array}{l}\text { Área da cozinha } \mathbf{~} \mathbf{m}^{2} \\
\text { por assento) }\end{array}$ & Tipo de alimentos preparados \\
\hline Cantina (140 lugares) & 0,4 & Pratos frios e quentes, alimentos de conveniência \\
\hline Restaurante popular (100 lugares) & 0,4 & Cardápio padronizado, refeições rápidas \\
\hline
\end{tabular}




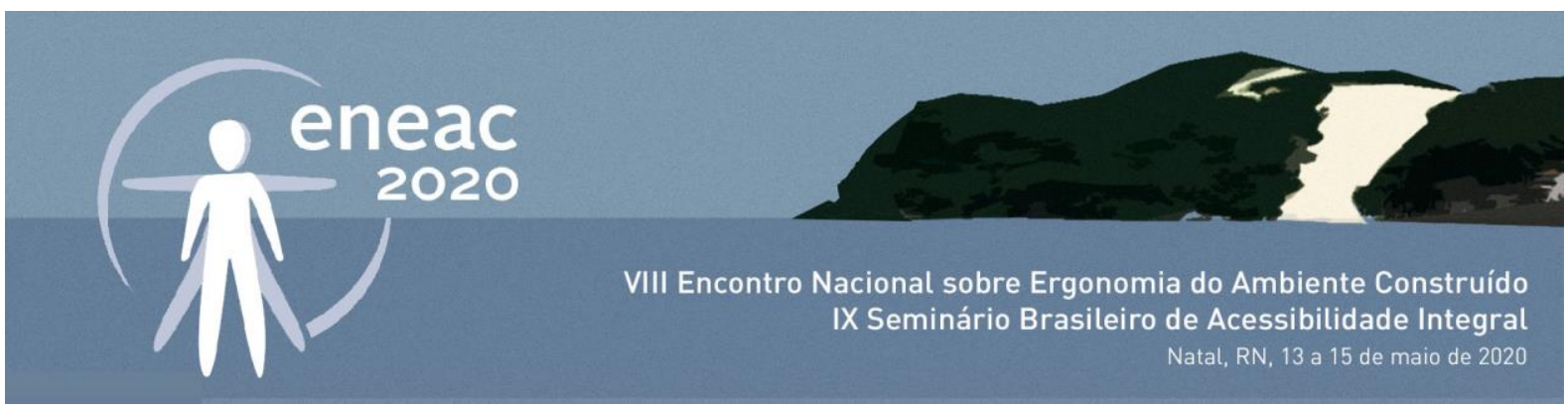

Tabela 2: Dimensionamento padrão para áreas de armazenamento e preparação de alimentos

\begin{tabular}{|l|c|l|}
\hline Ambiente/equipamento & Dimensão & Descrição \\
\hline Alcance máximo de prateleiras & $180 \mathrm{~cm}$ & $\begin{array}{l}\text { Adotar limite máximo para mulheres em pé, e altura } \\
\text { mínima, a partir do piso acabado de } 20 \mathrm{~cm} .\end{array}$ \\
\hline Distância entre prateleiras & $50 \mathrm{~cm}$ & $\begin{array}{l}\text { Distância mínima para movimentar objetos entre } \\
\text { prateleiras }\end{array}$ \\
\cline { 1 - 2 } Altura de bancadas de trabalho & $87-90 \mathrm{~cm}$ & Balcões e pias em cozinhas \\
\hline Largura de balcões & $60-75 \mathrm{~cm}$ & $\begin{array}{l}\text { Permitindo a separação, mas garantindo a visibilidade } \\
\text { entre os setores internos }\end{array}$ \\
\hline Largura de bancadas em ilha & $90-105 \mathrm{~cm}$ \\
\cline { 1 - 2 } $\begin{array}{l}\text { Altura de divisórias internas (se } \\
\text { houver) }\end{array}$ & $120 \mathrm{~cm}$ & $\begin{array}{l}\text { A fim de permitir a circulação de 2 pessoas, o acesso } \\
\text { aos móveis e prateleiras baixas e abertura de fornos. }\end{array}$ \\
\hline $\begin{array}{l}\text { Espaço mínimo para circulação interna } \\
\text { (cozinha) }\end{array}$ & $120 \mathrm{~cm}$ & \\
\hline
\end{tabular}

Fonte: adaptado de Lawson, 2017.

\section{ANÁLISES DOS DADOS DOS ESTABELECIMENTOS DE ALIMENTAÇÃO}

As análises são fruto de dados coletados nos estabelecimentos de alimentação do Centro de Educação (CEDU/UFAL), da Faculdade de Medicina (FAMED/UFAL) e do Centro de Integração Comunitária (CIC/UFAL). Os três estabelecimentos são gerenciados por empresas terceirizadas distintas, que oferecem serviços de lanches, almoço e jantar, em dias letivos. São estabelecimentos de grande fluxo diário de clientes, sejam estudantes, professores, técnicos e outros visitantes que estejam no ambiente da UFAL.

\subsection{RESTAURANTE A (No Centro de Educação - CEDU/UFAL)}

- Análise Global do Ambiente:

O restaurante A localiza-se no piso térreo do Centro de Educação - CEDU/UFAL, e sua planta baixa é pequena em relação ao bloco onde localiza-se. O CEDU consta de um público de 700 estudantes e cerca de 60 servidores, que se distribuem em 02 cursos de graduação e 04 cursos de pós-graduação (especialização, mestrado e doutorado), funcionando nos turnos manhã, tarde e noite. 0 restaurante ocupa o centro da UA, servindo também como passagem de usuários, ocupando uma área de $65,24 \mathrm{~m}^{2}$. O fluxo de usuários do restaurante do CEDU extrapola o público interno, atendendo também estudantes e professores de outras UAs, que frequentam o local.

- Identificação da Configuração Ambiental:

A planta baixa descrita na figura 02 mostra a distribuição dos espaços internos (área de mesas, bufê, caixa, atendimento e cozinha). A edificação é construída em alvenaria convencional com telhado de cerâmica, inclinação $25 \%$, piso em granilite, paredes pintadas em amarelo claro. As janelas são metálicas com fechamento em vidro.

O mobiliário do salão conta com 14 mesas plásticas de 4 lugares, totalizando 54 assentos (existem mesas e cadeiras extra empilhadas em caso de necessidade), 2 aparelhos de buffets, 1 balança de 

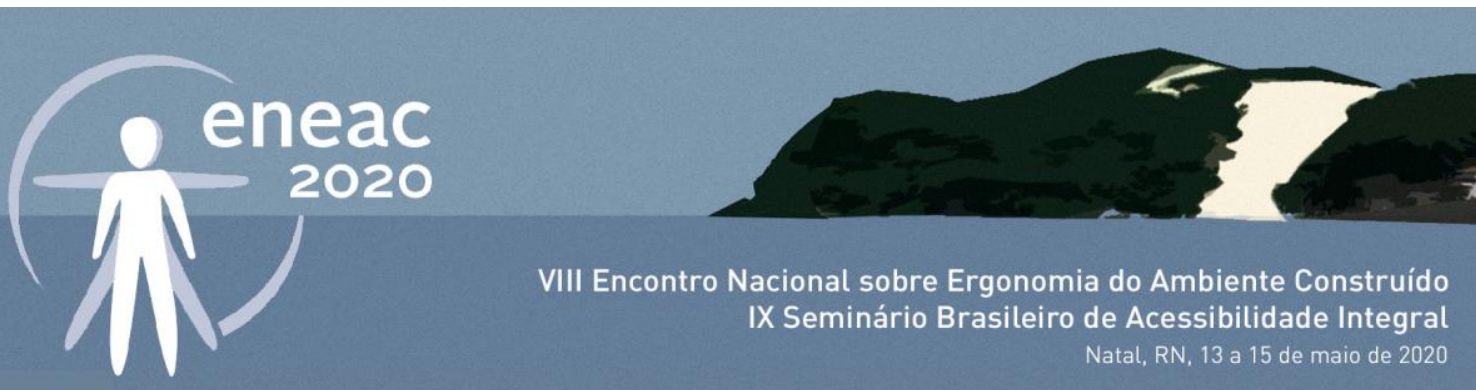

VIII Encontro Nacional sobre Ergonomia do Ambiente Construído IX Seminário Brasileiro de Acessibilidade Integral Natal, RN, 13 a 15 de maio de 2020

pesagem, 1 móvel para o caixa, 2 freezers verticais e 3 freezers horizontais. 0 mobiliário da cozinha dispõe de 1 balcão, 1 pia em inox, 1 fogão (4 bocas), 1 geladeira e 1 armário superior. Não há deposito ou espaço suficiente para o armazenamento dos alimentos e toda conservação de alimentos é improvisada. Com relação ao conforto ambiental, percebe-se que a orientação geográfica do prédio (fachada principal a norte), e a tipologia de pátio interno favorecem a boa circulação de ar, e o sombreamento das áreas de permanência.

Figura 2:- Planta Baixa do Restaurante A.

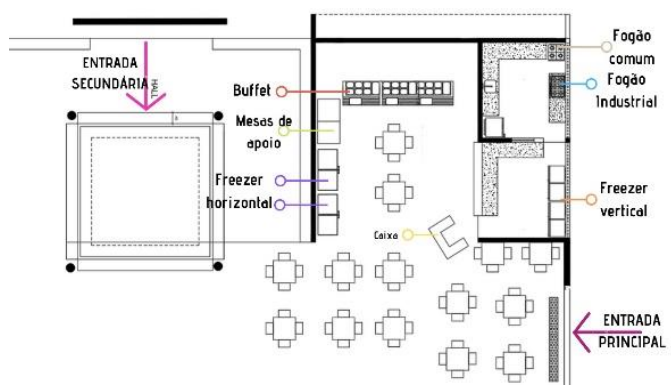

Fonte: os autores.

Figura 3: Vistas do salão de mesas, destacando (a) o balcão, (b) a fila para o caixa, e (c) cozinha e suas trabalhadoras em horário de pico.
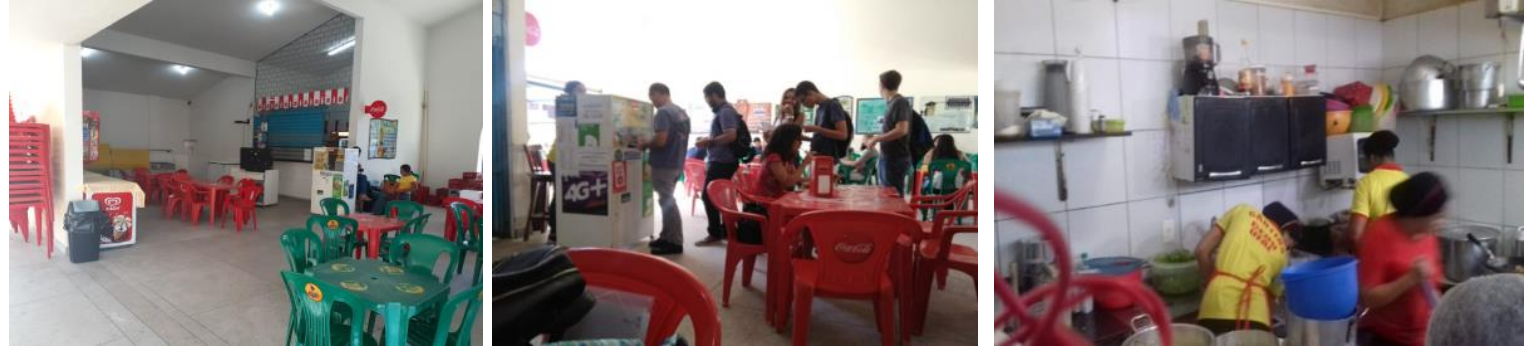

Fonte: os autores.

A aferição de conforto ambiental foi realizada com aplicativos para Android (Lux Meter, Decibel Xe Termômetro digital) a análise comparativa com as normas: NBR 5413 (ABNT, 1992), NBR 10.152 (ABNT,2017) e com Lamberts et al. (2014). Os resultados obtidos constam na Tabela 03.

Tabela 3: Dados da aferição do conforto térmico e acústico, obtidos no Restaurante A.

\begin{tabular}{|c|c|c|l|}
\hline $\begin{array}{c}\text { FATOR } \\
\text { ANALISADO }\end{array}$ & $\begin{array}{c}\text { ÍNDICE } \\
\text { OBTIDO }\end{array}$ & $\begin{array}{c}\text { ÍNDICE } \\
\text { RECOMENDADO }\end{array}$ & OBSERVAÇÕES \\
\hline Temperatura & $28^{\circ} \mathrm{C}$ & $\begin{array}{c}23 \text { a } 27^{\circ} \mathrm{C} \text { (Lamberts et } \\
\text { al., 2014) }\end{array}$ & Valor um pouco acima do recomendado. \\
\hline Ruído (dB) & $96 \mathrm{~dB}$ & $\begin{array}{c}40 \text { a } 50 \\
\text { (NBR 10152, 2017) }\end{array}$ & Valor muito acima do recomendado. \\
\hline Iluminação & - & - & - \\
\hline $\begin{array}{c}\text { Ponto 1 } \\
\text { (circ. geral) }\end{array}$ & 104,2 lux & $\begin{array}{c}100-150-200 \\
\text { (NBR 5413, 1992) }\end{array}$ & $\begin{array}{l}\text { O índice de iluminação sobre as mesas de alimentação está } \\
\text { adequado }\end{array}$ \\
\hline
\end{tabular}




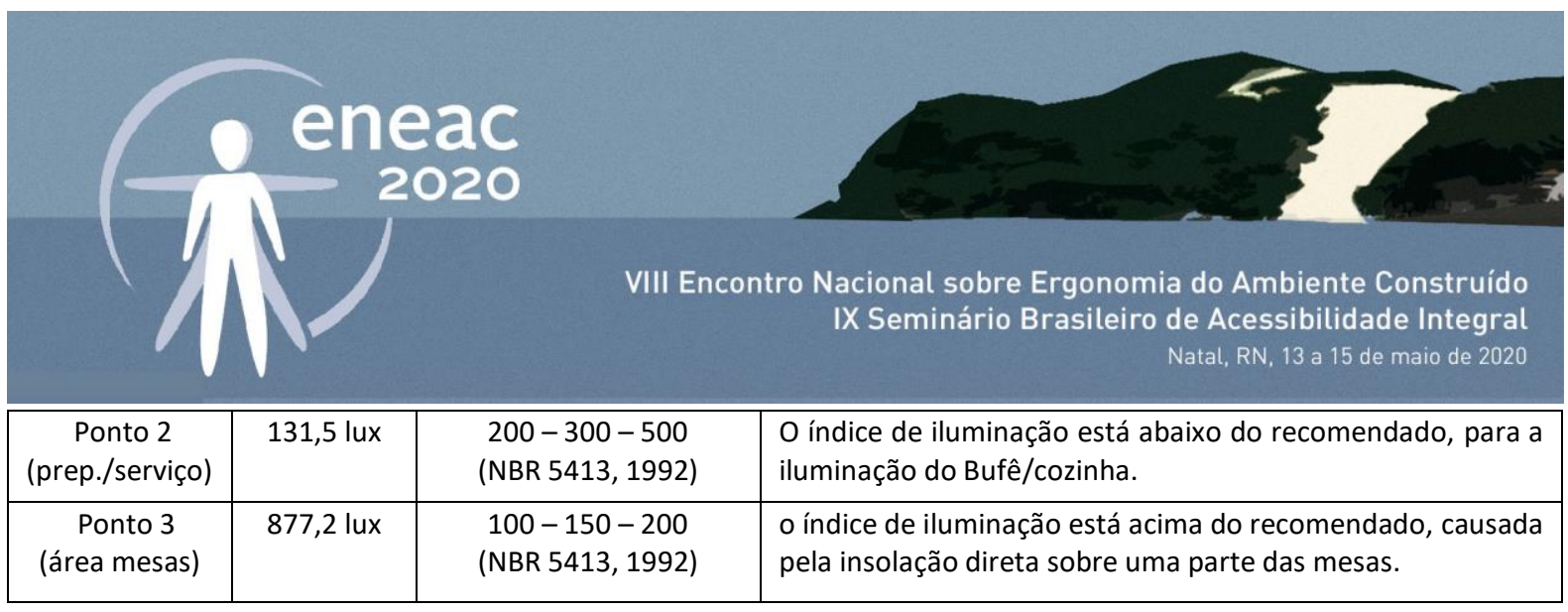

Fonte: Os autores.

- Análise do Ambiente em Uso:

O fluxo inicial de pessoas neste ambiente se dá por meio de dois acessos, uma porta principal e um pátio central da UA (Figura 4). Os usuários permanecem principalmente no centro do salão de mesas, nas proximidades do pátio, causando obstrução aos transeuntes. O layout do ambiente de mesas é flexível, de modo a permitir a mudança na posição das mesas e de cadeiras no salão. 0 excesso de mesas e cadeiras dificultam a acessibilidade plena, pois as distâncias mínimas de circulação, por vezes não são respeitadas. Na cozinha existem 1 fogão industrial, 1 geladeira, 1 bancada e 2 prateleiras baixas para o armazenamento de alimentos. $O$ armazenamento também acontece em cima da geladeira e em cestos no chão, por não haver armários suficientes. A fila de clientes no autosserviço muitas vezes coincide com a área de mesas e a fila do caixa, causando obstruções no fluxo, especialmente durante o almoço.

Figura 4: Mapa de fluxo dos usuários no ambiente do Restaurante $A$.
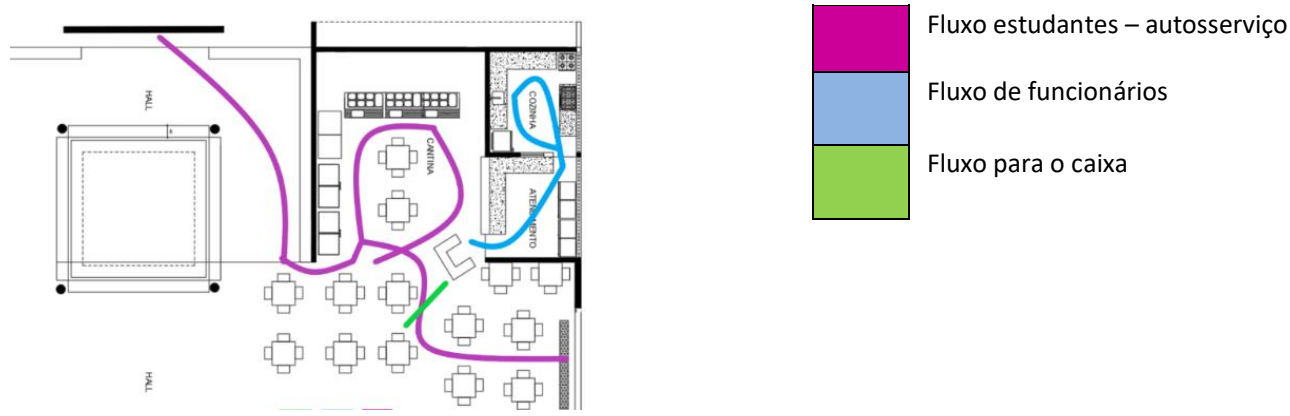

Fonte: Os autores.

- Análise da Percepção dos Usuários:

Em entrevista, funcionários relataram que o espaço da cozinha é muito pequeno para as atividades de preparação e armazenamento dos alimentos, nas quais trabalham cerca de 04 pessoas.

\subsection{RESTAURANTE B (NO CENTRO DE INTERESSE COMUNITÁRIO - CIC/UFAL)}

- Análise Global do Ambiente:

O Restaurante B serve lanches, almoço e jantar em sistema de autosserviço. É um dos estabelecimentos de alimentação com maior frequência de clientes do Campus A. C. Simões. Seu funcionamento é de segunda à sexta-feira, das $07 \mathrm{~h} 30$ às $20 \mathrm{~h}$. 0 estabelecimento é em formato semiaberto, construído em alvenaria convencional, coberto por laje de concreto armado. A pintura das paredes é em tom bege claro e o piso é em granilite polido. O revestimento interno das paredes da cozinha é em cerâmica esmaltada. A IES construiu e entregou o espaço ao prestador do serviço, que por conta própria mobiliou e equipou seu restaurante, com base em sua experiência no ramo. 


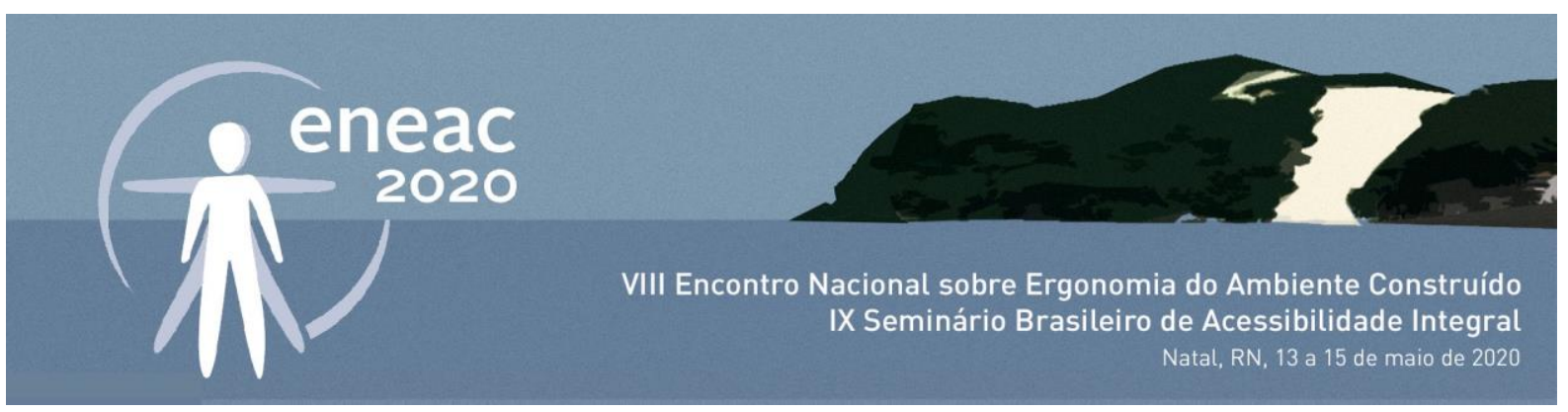

- Identificação da Configuração Ambiental:

O layout do restaurante é distribuído em área de mesas, caixa, área de autosserviço (ou bufê), exposição de lanches e cozinha, ocupando $50,26 \mathrm{~m}^{2}$ (ver Figura 5). A análise técnica do layout identificou conflitos no fluxo de clientes, com a forma de exposição dos produtos, e da organização dos equipamentos. $\mathrm{O}$ ambiente é confuso, não apresenta conforto físico, embora a área de mesas seja espaçosa.

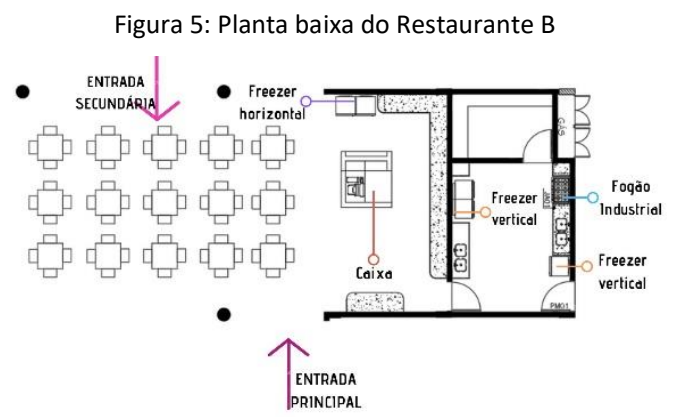

Fonte: Os autores.

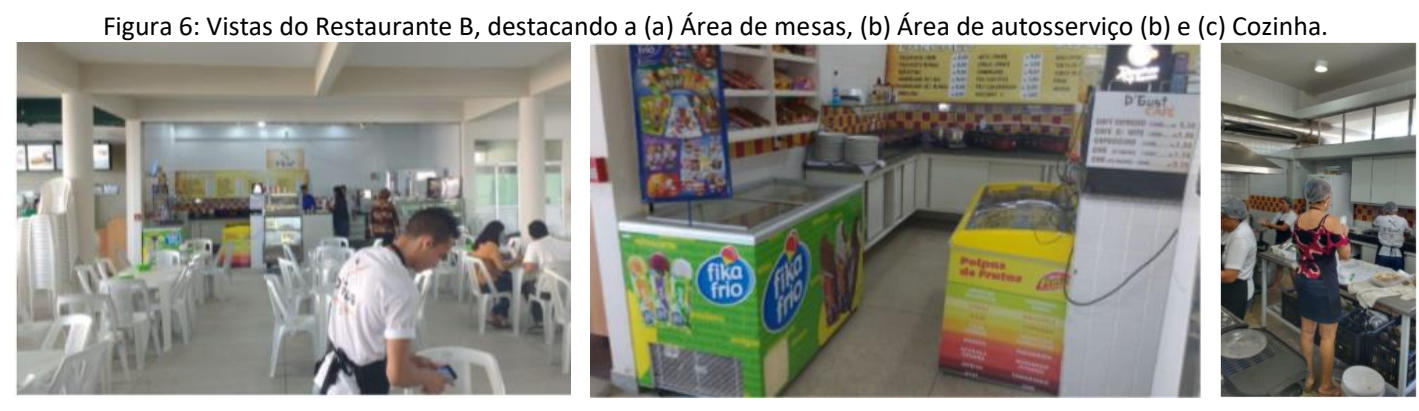

Fonte: os autores.

O CIC/UFAL é um prédio semiaberto, com pátio central e pé direito duplo, assim a iluminação e a ventilação naturais são de boa qualidade. A aferição das condições de conforto ambiental foi feita por meio de aplicativos para Android (Light Meter, Decibel X) e a análise comparativa com as normas: NBR 5413 (ABNT,1992), NBR 10.152 (ABNT, 2017) e com Lamberts et al. (2014), como demonstrado na Tabela 4.

Tabela 4: Dados da aferição do conforto térmico e acústico, obtidos no Restaurante B.

\begin{tabular}{|c|c|c|l|}
\hline $\begin{array}{c}\text { FATOR } \\
\text { ANALISADO }\end{array}$ & ÍNDICE OBTIDO & $\begin{array}{c}\text { ÍNDICE } \\
\text { RECOMENDADO }\end{array}$ & OBSERVAÇÕES \\
\hline $\begin{array}{c}\text { Temperatura } \\
\left({ }^{\circ} \mathrm{C}\right)\end{array}$ & $27^{\circ} \mathrm{C}$ & $\begin{array}{c}23^{\circ} \text { a } 27^{\circ} \mathrm{C} \\
\text { (Lamberts et al., 2014) }\end{array}$ & Adequado \\
\hline Ruído (dB) & $89 \mathrm{~dB}$ & $\begin{array}{c}40 \text { a } 50 \mathrm{~dB} \\
\text { (NBR } 10152,2017)\end{array}$ & Valor muito acima do recomendado \\
\hline Iluminação (Lux) & - & - & - \\
\hline
\end{tabular}




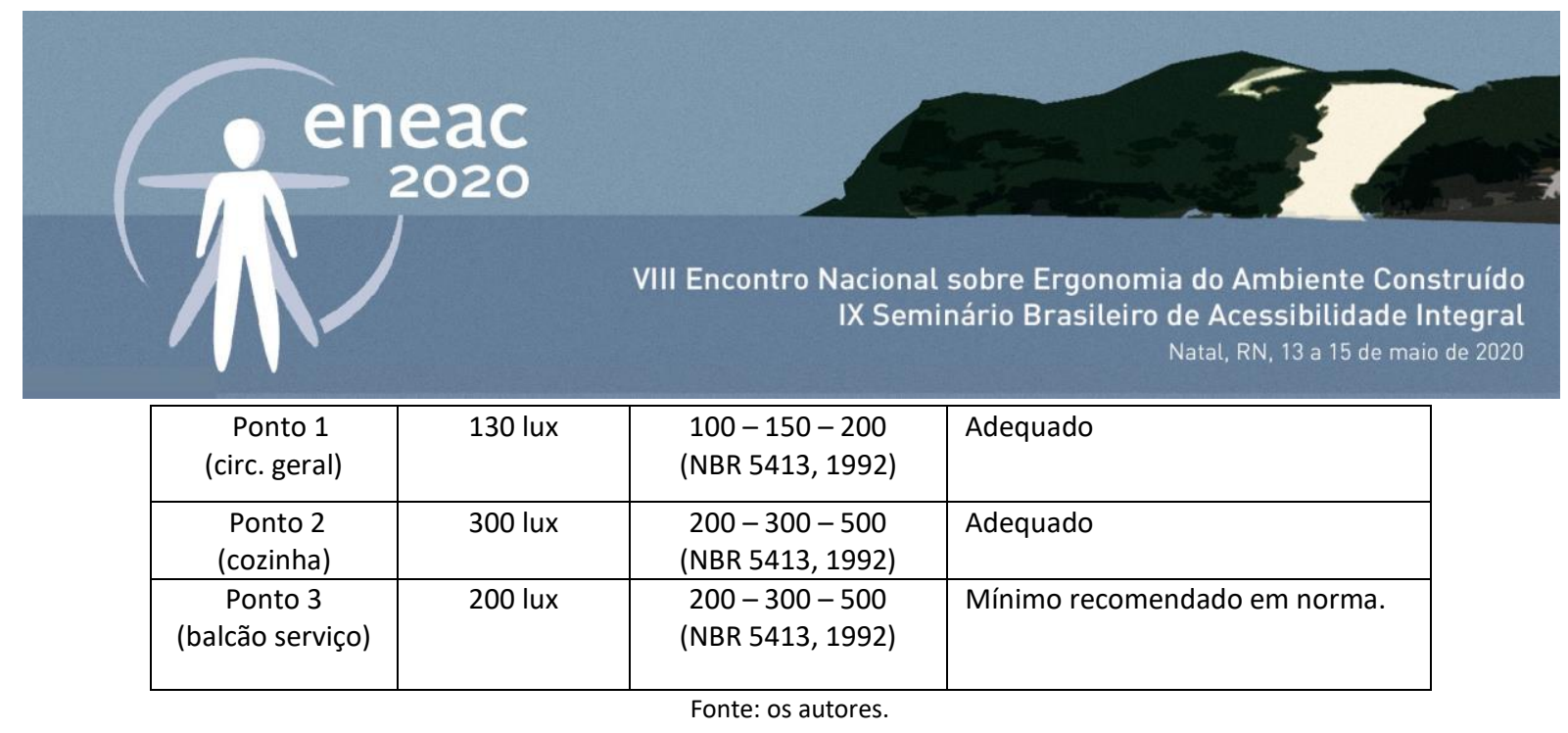

Com base nos dados coletados, a iluminação atendeu aos critérios estabelecidos em norma, gerando bem-estar e favorecendo a execução adequada das tarefas de preparo dos alimentos. Sobre o desempenho acústico, os valores obtidos encontravam-se bem acima da recomendação em norma, gerando desconforto auditivo aos clientes do estabelecimento. Percebe-se que a variação de temperatura, no restaurante $B$, está no limite do recomendado, entretanto, um maior desconforto foi percebido na área interna da cozinha, onde existem várias fontes de calor e poucas aberturas para ventilação.

- Análise do Ambiente em Uso:

A área de autosserviço tem circulação muito apertada, não é acessível, nem intuitiva para o cliente. Devido ao pouco espaço e o excesso de elementos, a compreensão do serviço oferecido é confusa. Durante o horário de pico (almoço), a circulação na área de autosserviço se confunde com a fila do caixa. A disposição dos refrigeradores verticais e horizontais atrapalham a circulação, obstruindo a passagem dos clientes e também, dos funcionários, durante 0 abastecimento de alimentos no bufê. Em geral, o ambiente é limpo e bem mantido. $O$ atendimento é rápido e simples. A Figura 7 demonstra os fluxos principais percebidos no ambiente (roxo para fluxo de estudantes no autosserviço, verde para o fluxo de pagamento junto ao caixa e azul para o fluxo de funcionários durante o trabalho).

Não há espaço de descanso de funcionários, que se sentam nas mesas dos clientes para realizar suas refeições. 0 grupo de 07 funcionários, sendo 02 cozinheiras, e os demais são ajudantes e trabalham no atendimento, dividindo funções de atendente, caixa, garçom e manutenção das mesas. Essa falta de divisão de funções prejudica a organização do trabalho por pessoa, e o projeto dos postos de trabalho, com base em princípios ergonômicos, como preconiza normas como a NR-17 (MT, 1990) sobre ergonomia no ambiente de trabalho. As condições de acessibilidade física impedem o acesso de cadeirantes, especialmente na área do autosserviço.

Figura 7: Mapa de uso e fluxos do Restaurante B.
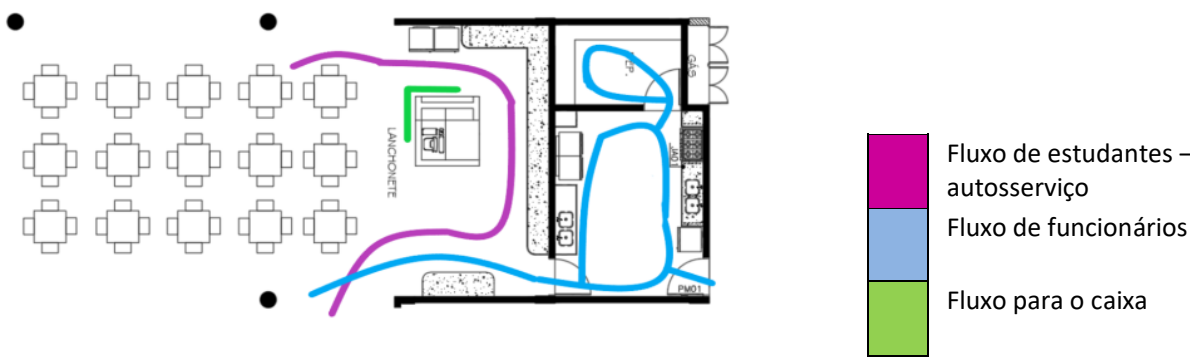

Fonte: os autores. 

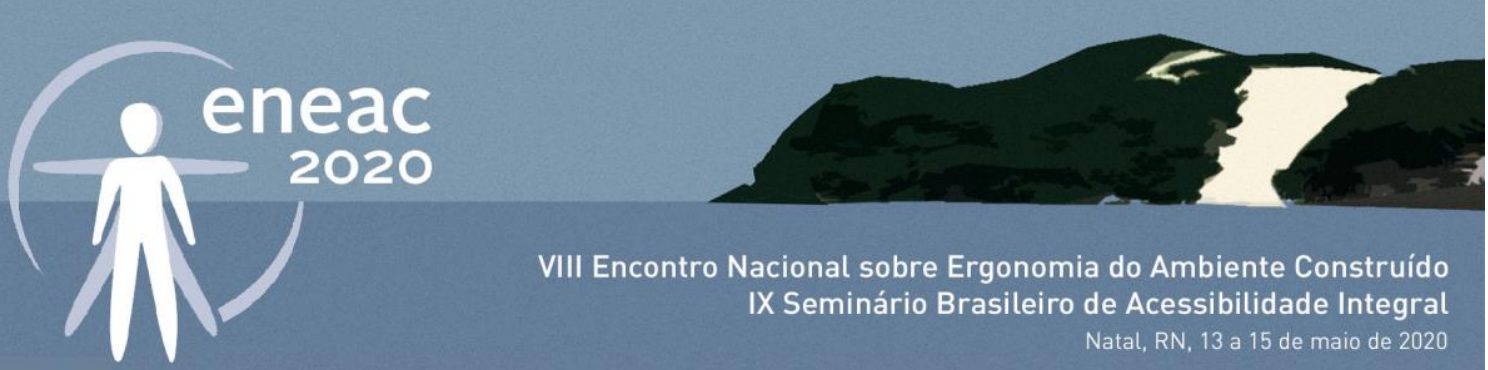

VIII Encontro Nacional sobre Ergonomia do Ambiente Construído IX Seminário Brasileiro de Acessibilidade Integral Natal, RN, 13 a 15 de maio de 2020

Analisando o comportamento dos clientes ao utilizarem o estabelecimento e suas instalações, percebe-se que as dimensões de circulação entre os móveis e equipamentos são inadequadas e insuficientes. A área ao redor do caixa fica sempre congestionada e não existe um sistema de atendimento por senhas, o que dificulta o atendimento nos horários de pico. O Restaurante $B$ apresentou diversas dificuldades por não apresentar um projeto de interiores na sua concepção. Porém, o local é agradável, e possui um atendimento de qualidade. Contudo, pode-se afirmar que um projeto de interiores, indiscutivelmente, seria o essencial para uma loja de alimentos funcional.

\subsection{RESTAURANTE C (NA FACULDADE DE MEDICINA - FAMED/UFAL)}

- Análise Global do Ambiente:

O restaurante $C$ fica localizado na UA da Faculdade de Medicina (FAMED/UFAL). O estabelecimento atende os alunos da FAMED e também do Hospital Universitário (HUPAA/UFAL) e demais membros da comunidade acadêmica que se deslocam até este bloco para almoçar. A edificação é feita de alvenaria convencional com telhado de telha canal, inclinação $25 \%$, o piso é granilite, com as paredes pintadas em branco.

- Identificação da Configuração Ambiental:

O restaurante é localizado junto a um pátio semiaberto, que funciona como circulação geral. A cozinha tem janelas em vidro (sem abertura) e é totalmente revestida em cerâmica 10x10 branca. 0 restaurante ocupa uma área de $98,97 \mathrm{~m}^{2}$, conforme a planta baixa da Figura 8 .

Figura 8: Planta baixa do Restaurante $C$

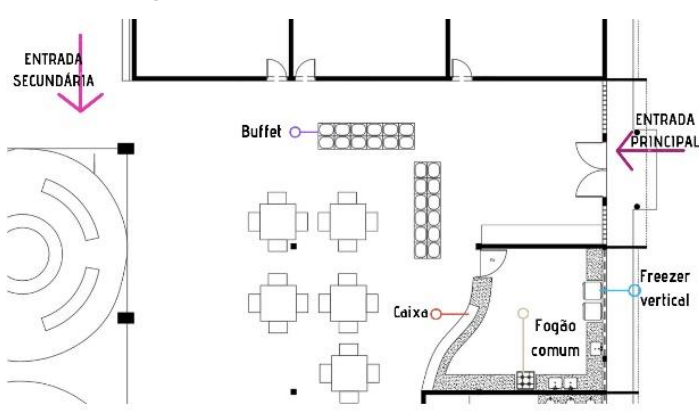

Fonte: Os autores.

Figura 9: Vistas do Restaurante C, sendo (a) salão de mesas e bufê ao fundo, (b) cozinha.
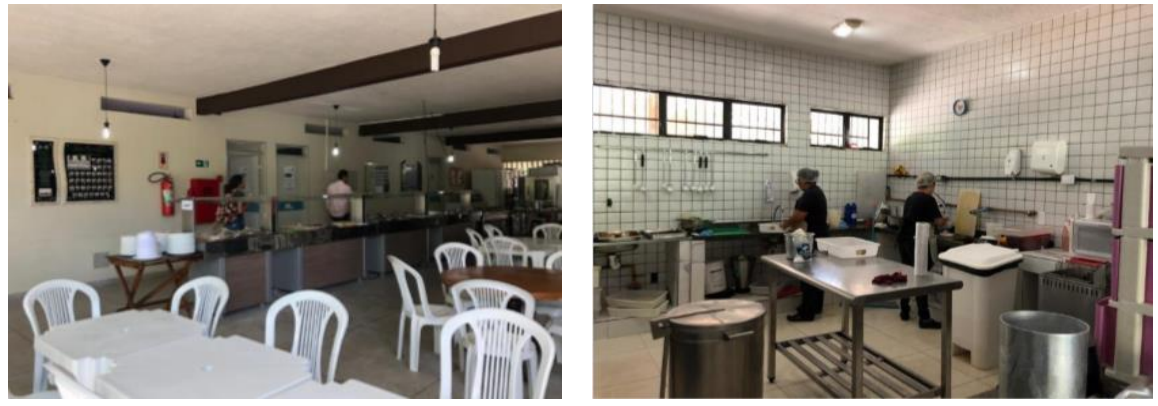

Fonte: os autores. 


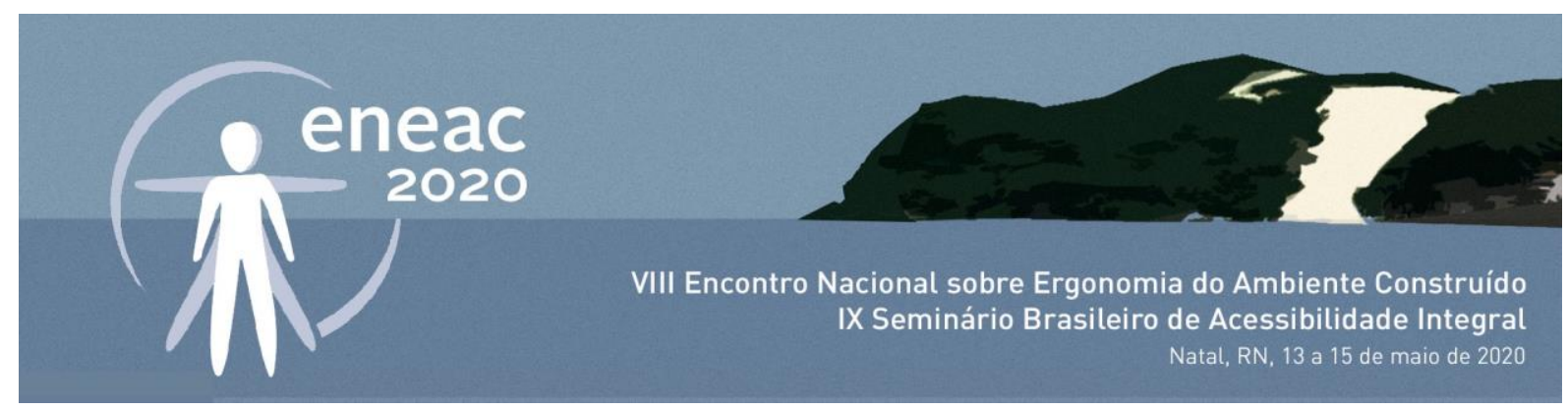

A aferição das condições de conforto ambiental foi feita por meio de aplicativos para Android (Light Meter, Decibel X) e a análise comparativa com as normas: NBR 5413 (ABNT,1992), NBR 10.152 (ABNT,2017) e com Lamberts et al. (2014), como demonstrado na Tabela 5.

Tabela 5: Valores de iluminância, temperatura e ruído do Restaurante C.

\begin{tabular}{|c|c|c|c|}
\hline $\begin{array}{c}\text { FATOR } \\
\text { ANALISADO }\end{array}$ & ÍNDICE OBTIDO & $\begin{array}{c}\text { ÍNDICE } \\
\text { RECOMENDADO }\end{array}$ & OBSERVAÇÕES \\
\hline Temperatura ( ${ }^{\circ} \mathrm{C}$ ) & $29^{\circ} \mathrm{C}$ & $\begin{array}{c}23^{\circ} \text { a } 27^{\circ} \mathrm{C} \\
\text { (Lamberts et al., 2014) }\end{array}$ & Temperatura acima da recomendada \\
\hline Ruído (dB) & $78,23 \mathrm{~dB}$ & $\begin{array}{c}40 \text { a } 50 \mathrm{~dB} \\
\text { (NBR } 10152,2017)\end{array}$ & Valor acima do recomendado \\
\hline $\begin{array}{c}\text { Iluminação (Lux) } \\
\text { Ponto 1 }\end{array}$ & - & - & \\
(circ. geral) & 300 lux & $\begin{array}{c}100-150-200 \\
\text { (NBR 5413, 1992) }\end{array}$ & Valor acima do recomendado \\
\hline $\begin{array}{c}\text { Ponto 2 } \\
\text { (cozinha) }\end{array}$ & 110 lux & $\begin{array}{c}200-300-500 \\
\text { (NBR 5413, 1992) }\end{array}$ & Valor abaixo do recomendado \\
\hline $\begin{array}{c}\text { Ponto 3 } \\
\text { (área bufê) }\end{array}$ & 115,5 lux & $\begin{array}{c}200-300-500 \\
\text { (NBR 5413, 1992) }\end{array}$ & Valor abaixo do recomendado \\
\hline
\end{tabular}

Fonte: os autores.

Dos resultados sobre temperatura e ruído, embora estejam acima do recomendado são pouco percebidos, pois a vegetação no pátio semiaberto ajuda no controle da temperatura e da dispersão do ruído de fundo, criando um microclima favorável. O restaurante dispõe de muita iluminação natural (na área de mesas) e poucos pontos de iluminação artificial (especialmente na cozinha, que é escura para as atividades de preparo de alimentos), o que compromete a visibilidade em todo o dia, principalmente nos dias nublados. Quanto ao mobiliário, o restaurante conta com mesas e cadeiras na área de consumo de alimentos (maior permanência dos clientes), bufê expositor de alimentos quentes e frios, complementado por mesas em linha (para sobremesas). Internamente na cozinha, existem: 01 fogão industrial em ilha, 01 freezer, 01 geladeira, várias lixeiras e mesas auxiliares de preparo.

- Análise do Ambiente em Uso:

A análise comportamental foi feita durante o horário da manhã, entre as 10:00h às 10:30, durante o intervalo entre as aulas. A figura 10 mostra o fluxo de usuários (em roxo, os estudantes que compram alimentos e cruzam a UA em direção ao HUPAA, em verde a fila para o pagamento, e em azul o fluxo de funcionários do restaurante). 


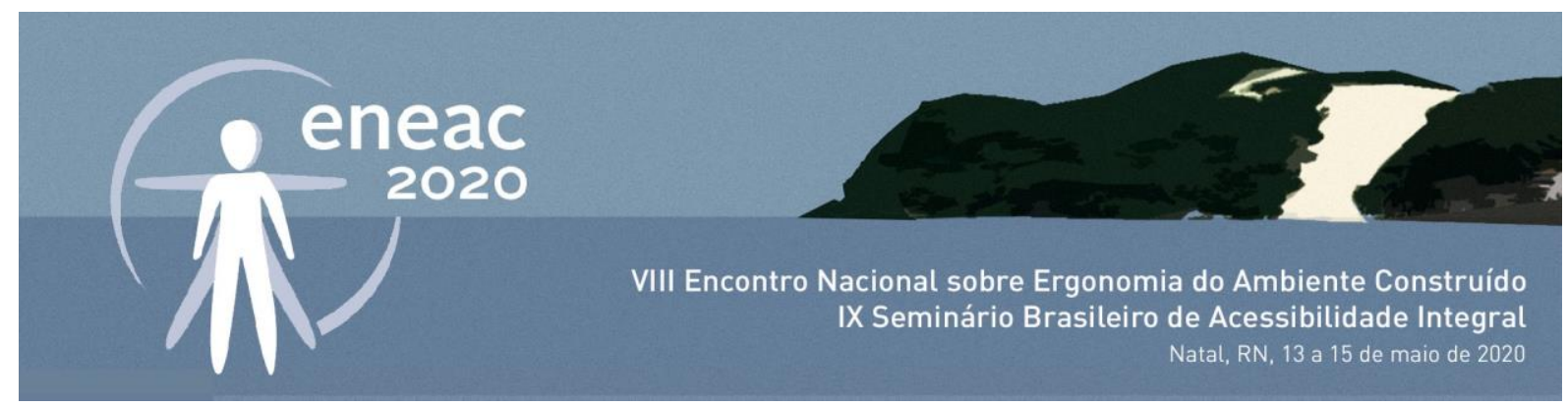

Figura 10: Mapa de uso e fluxos do Restaurante C.

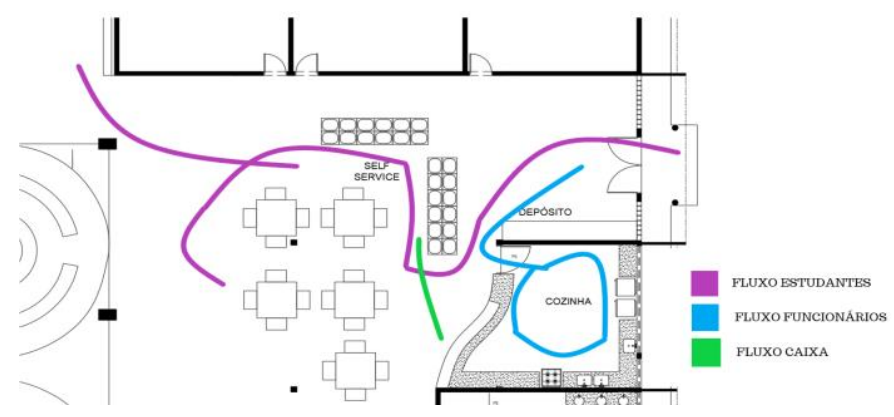

Fonte: os autores.

Estes fluxos implicam em regiões conflituosas, já que coincidem com pessoas que permanecem nas mesas, o fluxo de serviço (carga e descarga, retirada do lixo) e o fluxo para os banheiros. O locador do restaurante usa o espaço de circulação para distribuição de mesas e do bufê, implicando em má organização espacial, pouco espaço para circulação geral e ocupação de pessoas que desejam usar o pátio para outras finalidades. Um grande problema é o tempo de exposição dos alimentos, que estão no fluxo entre a Famed a o HUPPA. Não há devida proteção dos alimentos, e o bufê funciona como divisor entre o fluxo de serviço dos clientes e o fluxo de circulação Famed - HUPPA. Não há espaço para armazenamento dos alimentos, ou para refrigeração, os alimentos ficam armazenados num armário na circulação. A cozinha é pequena e mal organizada, os refrigeradores ficam expostos na circulação, a área de carga e descarga é desprotegida.

- Análise da percepção dos usuários:

Em entrevistas aos usuários (funcionários e clientes), um dos membros da equipe do restaurante informou que a situação é precária pelo fato da IES não permitir ajustes no espaço físico, que já solicitaram melhorias, mas não receberam resposta.

\section{ANÁLISE ERGONOMICA COMPARATIVA ENTRE OS ESTABELECIMENTOS COMERCIAIS}

A fim de obter-se uma comparação entre os três estabelecimentos analisados, elaboraram-se quadros sintéticos por categorias, sendo o Quadro 2 sobre os dados físicos (condição geral, acessibilidade, dimensionamento) e o Quadro 3 sobre o comportamento e a percepção dos usuários.

Quadro 2: Comparação entre dados físicos dos Restaurantes A, B e C.

\begin{tabular}{|c|c|c|c|c|c|}
\hline REST. & $\begin{array}{c}\text { ÁREA } \\
\text { CONSTRUÍDA } \\
\left(\mathrm{m}^{2}\right)\end{array}$ & CONDIÇÃO GERAL & $\begin{array}{l}\text { ESPAÇO PARA } \\
\text { OS CLIENTES }\end{array}$ & $\begin{array}{l}\text { CIRCULAÇÃO E } \\
\text { ACESSIBILIDADE }\end{array}$ & $\begin{array}{l}\text { ESPAÇOS INTERNOS } \\
\text { (COZINHA E OUTROS) }\end{array}$ \\
\hline \multirow[t]{2}{*}{$A$} & $\begin{array}{l}65,24 \text { (geral) } \\
\text { sendo: }\end{array}$ & \multirow{2}{*}{$\begin{array}{l}\text { Salão e cozinha não } \\
\text { obedecem aos } \\
\text { padrões normativos } \\
\text { para os tipos de } \\
\text { ambiente, layout não } \\
\text { planejado, }\end{array}$} & \multirow{2}{*}{$\begin{array}{l}\text { Mesas e cadeiras } \\
\text { de plástico, leves } \\
\text { e passíveis de } \\
\text { mudança de } \\
\text { layout, condição } \\
\text { de conforto }\end{array}$} & \multirow{2}{*}{$\begin{array}{l}\text { Fluxos pouco } \\
\text { conflituosos na área } \\
\text { dos clientes, } \\
\text { especialmente junto } \\
\text { ao caixa. No interior } \\
\text { dos ambientes de }\end{array}$} & \multirow{2}{*}{$\begin{array}{l}\text { Mobiliário e utensílios } \\
\text { improvisados, não } \\
\text { oferecem segurança } \\
\text { para os trabalhadores, } \\
\text { nem segurança } \\
\text { alimentar para os }\end{array}$} \\
\hline & $\begin{array}{l}13,15 \\
\text { (cozinha) }\end{array}$ & & & & \\
\hline
\end{tabular}




\begin{tabular}{|c|c|c|c|c|c|}
\hline \multicolumn{6}{|c|}{$\begin{array}{l}\text { VIII Encontro Nacional sobre Ergonomia do Ambiente Construído } \\
\qquad \text { IX Seminário Brasileiro de Acessibilidade Integral } \\
\text { Natal, RN, } 13 \text { a } 15 \text { de maio de } 2020\end{array}$} \\
\hline & $\begin{array}{l}41,24 \text { (salão e } \\
\text { bufê) }\end{array}$ & $\begin{array}{l}\text { entretanto simples e } \\
\text { funciona } \\
\text { razoavelmente bem. } \\
\text { Área do caixa } \\
\text { apresenta conflito de } \\
\text { fluxo, não há } \\
\text { preocupação com } \\
\text { aspectos estéticos, } \\
\text { nem com variedade } \\
\text { de produtos. }\end{array}$ & $\begin{array}{l}\text { geral agradável } \\
\text { devida a boa } \\
\text { ventilação. }\end{array}$ & $\begin{array}{l}\text { serviço, cozinha e } \\
\text { lanchonete, o pouco } \\
\text { espaço e a falta de } \\
\text { organização } \\
\text { dificultam o trabalho. } \\
\text { Cozinha inacessível } \\
\text { segundo a NBR } 9050 \\
\text { (ABNT, 2015). }\end{array}$ & $\begin{array}{l}\text { clientes. A acessibilidade } \\
\text { e a ergonomia dos } \\
\text { postos de trabalho são } \\
\text { desprezadas. Calor } \\
\text { excessivo, pouco espaço } \\
\text { para manusear } \\
\text { utensílios, janelas } \\
\text { pequenas, iluminação } \\
\text { não planejada, } \\
\text { trabalhadores de pé } \\
\text { durante todo o período. }\end{array}$ \\
\hline \multirow[t]{4}{*}{$B$} & $\begin{array}{l}\text { 50,26 (geral) } \\
\text { sendo: }\end{array}$ & \multirow{4}{*}{$\begin{array}{l}\text { Áreas bem definidas } \\
\text { para cada tarefa. } \\
\text { Problemas de fluxo } \\
\text { no balcão de } \\
\text { autosserviço e caixa. } \\
\text { Equipamentos e } \\
\text { utensílios novos e } \\
\text { bem higienizados. } \\
\text { Layout geral } \\
\text { espontâneo, não } \\
\text { existe um conceito } \\
\text { estético. Informação } \\
\text { visual confusa e } \\
\text { ineficiente. }\end{array}$} & \multirow{4}{*}{$\begin{array}{l}\text { Mesas e cadeiras } \\
\text { de plástico, } \\
\text { possibilitando } \\
\text { flexibilidade e } \\
\text { rearranjos. } \\
\text { Espaço bem } \\
\text { ventilado, } \\
\text { agradável e } \\
\text { iluminado. Área } \\
\text { de autosserviço } \\
\text { inacessível, de } \\
\text { acordo com a } \\
\text { NBR 9050 } \\
\text { (ABNT, 2015). } \\
\end{array}$} & \multirow{4}{*}{$\begin{array}{l}\text { Boa acessibilidade na } \\
\text { área de mesas, mas o } \\
\text { fluxo é conflituoso e } \\
\text { inacessível no balcão } \\
\text { de autosserviço. O } \\
\text { acesso de serviço é } \\
\text { independente e } \\
\text { amplo. }\end{array}$} & \multirow{4}{*}{$\begin{array}{l}\text { Espaços relativamente } \\
\text { funcionais, } \\
\text { equipamentos } \\
\text { utensílios profissionais, } \\
\text { adequados a cozinhas } \\
\text { comerciais. Funcionários } \\
\text { trabalham em pé } \\
\text { durante todo o } \\
\text { expediente. Há espaços } \\
\text { definidos de preparo e } \\
\text { armazenamento. Lixo } \\
\text { fica exposto na cozinha, } \\
\text { mas há espaço no acesso } \\
\text { de serviço. }\end{array}$} \\
\hline & $\begin{array}{l}\text { 26,48 (salão } \\
\text { de mesas) }\end{array}$ & & & & \\
\hline & $\begin{array}{l}17,44 \\
\text { (cozinha) }\end{array}$ & & & & \\
\hline & $\begin{array}{l}6,34 \\
\text { (depósito) }\end{array}$ & & & & \\
\hline \multirow[t]{3}{*}{ C } & $\begin{array}{l}\text { 98,97 (geral) } \\
\text { sendo: }\end{array}$ & \multirow{3}{*}{$\begin{array}{l}\text { Cozinha com } \\
\text { organização } \\
\text { conflituosa, e layout } \\
\text { não planejado. Área } \\
\text { de armazenamento } \\
\text { totalmente } \\
\text { inadequada. Layout } \\
\text { geral não projetado, } \\
\text { fluxos conflituosos } \\
\text { no caixa. Melhor } \\
\text { conceito estético e } \\
\text { aparência na área de } \\
\text { clientes. } \\
\end{array}$} & \multirow{3}{*}{$\begin{array}{l}\text { Mesas e cadeiras } \\
\text { de plástico em } \\
\text { alguns pontos, e } \\
\text { madeira em } \\
\text { outros. } \\
\text { Mobiliário leves, } \\
\text { passíveis de } \\
\text { modificação de } \\
\text { layout, durante } \\
\text { o uso. }\end{array}$} & \multirow{3}{*}{$\begin{array}{l}\text { Fluxo conflituoso em } \\
\text { toda área de clientes } \\
\text { e autosserviço, } \\
\text { podendo haver risco } \\
\text { alimentar. } \\
\text { Acessibilidade } \\
\text { razoável no } \\
\text { autosserviço e na área } \\
\text { de mesas. A } \\
\text { proximidade com o } \\
\text { banheiro é um ponto } \\
\text { positivo. }\end{array}$} & \multirow{3}{*}{$\begin{array}{l}\text { Maior espaço de cozinha } \\
\text { entre os demais, e pouco } \\
\text { organizada, mas } \\
\text { funcional. } \\
\text { equipamentos } \\
\text { utensílios são } \\
\text { profissionais. Há muitas } \\
\text { lixeiras, o acesso de } \\
\text { serviço é inadequado e } \\
\text { exposto ao público. }\end{array}$} \\
\hline & $\begin{array}{l}72,47 \text { (salão e } \\
\text { bufê) }\end{array}$ & & & & \\
\hline & $\begin{array}{l}26,50 \\
\text { (cozinha) }\end{array}$ & & & & \\
\hline
\end{tabular}

Fonte: os autores.

Quadro 03: Dados da análise dos comportamentos e da percepção dos usuários

\begin{tabular}{|c|l|}
\hline $\begin{array}{c}\text { Usuários } \\
\text { observados }\end{array}$ & \multicolumn{1}{c|}{ DESCRIÇÃO } \\
\hline \multicolumn{1}{|c|}{ RESTAURANTE A } \\
\hline Clientes & $\begin{array}{l}\text { Expressaram descontentamento com a organização do layout, com pouca variedade de alimentos e } \\
\text { acúmulo de pessoas na fila do caixa. }\end{array}$ \\
\hline Funcionários & $\begin{array}{l}\text { Manifestaram desconforto com o mal dimensionamento da cozinha, com o calor excessivo, e o pouco } \\
\text { espaço para exercerem suas atividades. }\end{array}$ \\
\hline Proprietário & Não opinou \\
\hline \multicolumn{1}{|c|}{ RESTAURANTE B } \\
\hline Clientes & $\begin{array}{l}\text { Expressaram desconforto com a falta de informação visual, espacialmente sobre o cardápio, e a } \\
\text { identificação dos alimentos vendidos, a falta de organização da exposição dos produtos; demonstraram } \\
\text { desconforto com a instabilidade das mesas e cadeiras, a ponto de balançar muito durante as refeições. } \\
\text { Outros clientes afirmaram que o local do autosserviço é muito apertado, esbarrando uns nos outros. }\end{array}$ \\
\hline
\end{tabular}




\begin{tabular}{|c|l|}
\hline Funcionários & $\begin{array}{l}\text { No geral, os funcionários comentaram que a carga horária de trabalho é pesada, e a falta de um local } \\
\text { para descanso, torna o trabalho mais estressante. }\end{array}$ \\
\hline Proprietário & $\begin{array}{l}\text { O proprietário alega que não pode fazer alterações estruturais devido ser um espaço em instituição } \\
\text { pública. }\end{array}$ \\
\hline Clientes & $\begin{array}{l}\text { Manifestaram dificuldade com a circulação geral se confundir com o acesso ao balcão de autosserviço. } \\
\text { Demonstraram desconforto pelo proprietário usar mais espaço do pátio, do que os estudantes, e preços } \\
\text { dos alimentos serem mais altos que outros restaurantes no campus. }\end{array}$ \\
\hline Funcionários & $\begin{array}{l}\text { Para os funcionários, a má organização espacial dificulta o dia a dia de trabalho, e os conflitos de fluxo } \\
\text { também causam algumas tensões. }\end{array}$ \\
\hline Proprietário & $\begin{array}{l}\text { Sugere que a SINFRA, como órgão responsável, se pronuncie para melhoramento do ambiente como } \\
\text { todo. }\end{array}$ \\
\hline
\end{tabular}

Fonte: os autores.

\section{CONSIDERAÇÕES FINAIS}

As condições de desconforto e falta de planejamento percebidos neste estudo podem contribuir para que novos projetos de edificações de uso universitário possam ser elaborados com base em análises ergonômicas mais detalhadas. Devem ser considerados os dados de espaços similares, e dos usuários, para que os ambientes sejam adequados ao uso a que se destinam. Projetar o ambiente construído com base em critérios ergonômicos para as atividades prescritas podem amenizar erros e desconforto futuros de uso e ocupação dos ambientes, evitando gastos desnecessários com reformas e adaptações. O layout adequado delimita e organiza os espaços, para que o conforto humano seja prioritário no uso de espaços públicos, assim, o dimensionamento e a seleção de mobiliário e de equipamentos podem ser mais específicos e criteriosos, baseada em necessidades reais dos futuros usuários. As condições de conforto térmico, acústico e lumínico são essenciais para complementar o conforto psicológico e ergonômico. Esses aspectos foram desconsiderados nos projetos dos ambientes analisados.

O planejamento de um estabelecimento de alimentação deve envolver não apenas o mix de produtos a ser oferecido, mas a forma de apresentação e divulgação dos produtos, que envolve o design gráfico, a comunicação visual e a legibilidade da identidade da empresa em seus espaços internos e externos, a forma de organização dos ambientes e do mobiliário para que haja conforto, higiene e segurança física e alimentar para seus clientes, assim como um conceito estético a garantir a agradabilidade e a maior permanência de seus clientes. Esta organização espacial não pode ser visível apenas no salão de mesas, mas essencialmente em ambientes internos de trabalho, para que sejam garantidas a funcionalidade e a boa execução das tarefas de trabalho e as condições ergonômicas para os funcionários.

Apesar dos estabelecimentos estarem localizados em uma IES, as condições de uso e organização também dependem da gestão deste espaço, pelo locador, e também pela IES, que devem em conjunto oferecer um serviço de qualidade à comunidade universitária. Do pronto de vista do projeto arquitetônico, este deve atender às normas de acessibilidade e dimensionamento adequados, para que o uso dos espaços de trabalho possa garantir a ergonomia e o bem-estar de trabalhadores em condições de calor e risco em atividades de trabalho. 


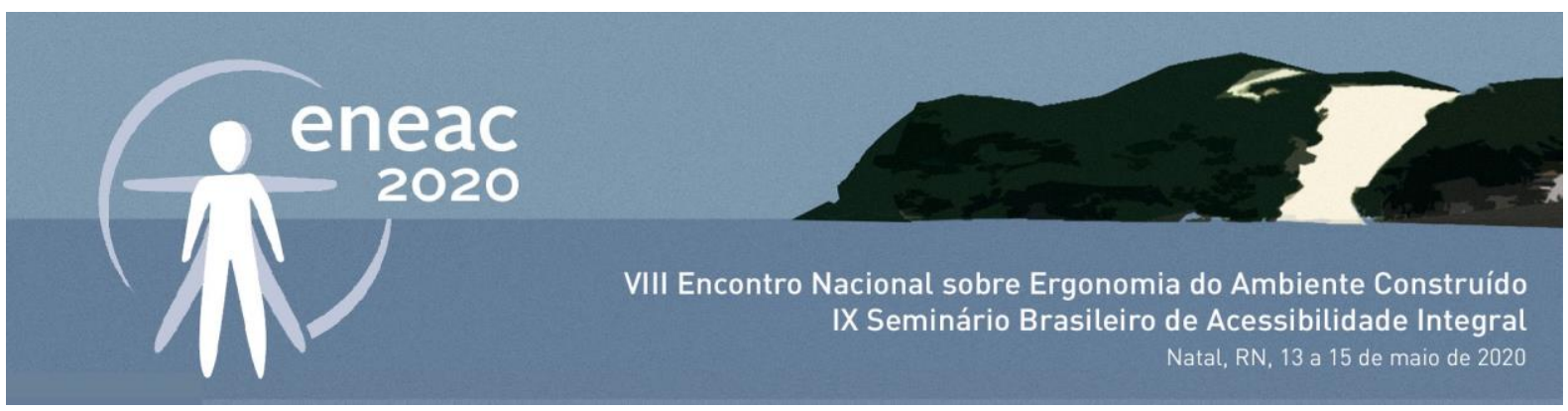

\section{REFERENCIAS}

ASSOCIAÇÃO BRASILEIRA DE NORMAS TÉCNICAS - ABNT. NBR 10.152 Acústica - Níveis de pressão sonora em ambientes internos a edificações. Rio de Janeiro, 2017, 21p.

ASSOCIAÇÃO BRASILEIRA DE NORMAS TÉCNICAS - ABNT. NBR 5413 lluminância de interiores. Rio de Janeiro, 1992, 13p. ASSOCIAÇÃO BRASILEIRA DE NORMAS TÉCNICAS - ABNT. NBR 9050 Acessibilidade a edificações, mobiliário, espaços e equipamentos urbanos. Rio de Janeiro, 2015, 148p.

LAMBERTS, Roberto; DUTRA, Luciano, PEREIRA, Fernando. Eficiência Energética na Arquitetura (3a EDIÇÃO). Florianópolis, Eletrobrás/PROCEL, 2014.

LAWSON, Fred. Restaurantes e equipamentos para serviços de alimentação. In: BUXTON, Pamela. Manual do Arquiteto, planejamento, dimensionamento e projeto. Ed. Bookman, 2017.

MACIEL, A. M.; COSTA, E.; LARANJEIRAS, G.; VILLAROUCO, V. Avaliação ergonômica de food trucks. In: Encontro Nacional de Ergonomia do Ambiente Construído, 8., Fortaleza, 2018. Anais [...], Fortaleza, UFC, 2018.

\section{MATOS, C.H. Condições de trabalho e estado nutricional de operadores do setor de} alimentação coletiva: um estudo de caso. Florianópolis, 2000. Dissertação (Mestrado em Engenharia de Produção) - Programa de Pós-graduação em Engenharia de produção, Universidade Federal de Santa Catarina, 2000.

SANT'ANA, H.M.P.; AZEREDO, R.M.C.; CASTRO, J.R. Estudo ergonômico em serviços de alimentação. Saúde em debate. n. 42, março, p.45-48, 1994.

SARMENTO, Thaisa F. C. S.; VILLAROUCO, Vilma. Projetar o ambiente construído com base em princípios ergonômicos. In: Simpósio Brasileiro de Qualidade do Projeto do Ambiente Construído, 6., Uberlândia, 2019. Anais [...] Uberlândia, UFU, 2019.

SILVEIRA, Carolina Morgado F.; BINS ELY, VERA HELENA MORO. Avaliação do trabalho dos atendentes em panificadora sob o viés da psicologia ambiental e da ergonomia. In: XIII ENCAC/ IX ELACAC - Encontro Nacional e Latino-Americano de Conforto no Ambiente Construído, 13., Campinas, 2015. Anais [...], Campinas, ANTAC, 2015.

VILLARROUCO, Vilma. Tratando de Ambientes Ergonomicamente Adequados: Seriam Ergoambientes? In: MONT'ALVÃO, Cláudia; VILLARROUCO, Vilma (Org.). Um Novo Olhar para o Projeto: a ergonomia no ambiente construído. Teresópolis, RJ: 2AB, p. 24-46, 2011.

VILLAROUCO, Vilma. An ergonomic look at the work environment. In: International Ergonomics Association Congress, 17. Beijing, 2009. Proceedings [...] Beijing, IEA, SPRINGER, 2009.

UNIVERSIDADE FEDERAL DE ALAGOAS. Censo Universitário de 2018. Disponível em: https://numeros.ufal.br/graduacao/numeros-gerais-da-graduacao-censo-2016/2018/censo-2018. Acesso em: 05 Dez. 2019. 